\title{
Avaliação de fatores de risco para o desenvolvimento de complicações perinatais na presença de cardiopatia materna
}

Autor: Clóvis Antônio Bacha

Orientador: Prof. Dr. Cézar Alencar de Lima Rezende

Tese apresentada ao Curso de Pós-Graduação em Medicina da Faculdade de Medicina, Universidade Federal de Minas Gerais, como requisito parcial à obtenção do título de Doutor em Medicina em 19 de dezembro de 1999.

Objetivo: avaliar fatores de risco para o desenvolvimento de complicações perinatais em gestação de pacientes portadoras de cardiopatia.

Metodologia: Estudo tipo Coorte Prospectivo. O grupo de estudo foi composto por gestantes portadoras de cardiopatia e seus conceptos acompanhados durante a gestação no SERGAR-HC, no período compreendido entre outubro de 1990 a setembro de 1997, que tiveram resolução da gestação na Maternidade do referido nosocômio e que foram avaliadas pelo mesmo examinador (o autor) anteriormente ao parto.

Fatores de exclusão: gestações gemelares; cardiopatia hipertensiva; doença de Chagas sem cardiopatia evidente; abortamentos. Foram avaliados 181 gestantes e seus conceptos. Variável resposta complicações perinatais na presença de cardiopatia materna (CPPC). Foram consideradas 30 variáveis dependentes, entre elas a classificação funcional (NYHA, 1979) e a classificação anatômica. Todas as que se mostraram estatisticamente significantes como fator de risco na análise univariada foram encaminhadas para a análise multivariada ( $\mathrm{p}<0,05)$.

Resultados: Freqüência das complicações perinatais: baixo peso - 18,20\%, concepto PIG 13,8\%, prematuro $12,7 \%$, Apgar 5' $<7=3,80 \%$ e $2,76 \%$ de mortalidade perinatal. Ocorreram dois óbitos maternos.

Análise univariada: as variáveis Doença Associada [Risco Relativo (Intervalo de confiança de 95\%) = 1,81 (1,05$311)]$, Classificação Anatômica [(2,31 $(1,44-3,70)]$, Hipertensão Pulmonar [2,09 (1,30-3,35)], Regurgitação Valvar Secundária [1,95 $(1,18-3,20)]$, Classificação Funcional no Início do Pré-Natal [(1,95 $(1,18-3,20)]$ e Descompensação Cardíaca $[1,82(1,13-2,92)]$ mostraram-se fatores de risco.

Análise multivariada: apenas a Classificação Anatômica mostrou estar independentemente associada ao desenvolvimento de CPPC com uma ODDS corrigida de $3,29(1,65-6,56)$.

Palavras-chave: Mortalidade perinatal. Resolução da gestação. Cardiopatias na gravidez.

Quimioterapia neoadjuvante para o tratamento de portadoras do câncer de colo uterino (EC II e III): avaliação clínica, laboratorial, imunológica, psicológica e ultra-somográfica, comparada ao indice de resposta

Autora: Ceres Nunes de Resende Orientador: Prof. Dr. Carlos Roberto de Resende Miranda

Co-orientador: Prof. Dr. Aderson Luiz Costa Junior

Dissertação apresentada à Faculdade de Ciências da Saúde da Universidade de Brasília, para a obtenção do Título de Mestre em Ciências da Saúde em 23 de julho de 1999.

Objetivamos avaliar a resposta ao tratamento quimioterápico neoadjuvante a três ciclos de cisplatina $\left(75 \mathrm{mg} / \mathrm{m}^{2}\right)$ e ifosfamida $\left(1 \mathrm{~g} / \mathrm{m}^{2}\right)$. Estudamos 22 pacientes portadoras de carcinoma epidermóide invasor do colo uterino estadiamento II ou III. Avaliamos o Índice de Resposta Objetiva (IRO) e Índice de Operabilidade (IO) comparados ao perfis: clínico, laboratorial, imunológico (Teste Cutâneo de Hipersensibilidade Retardada ou TCHR), psicológico (Beck Depression Inventory ou BDI) e ecográfico transvaginal, antes e após o tratamento quimioterápico. A média de idade foi de 40 anos (29 a 57 anos). O IRO foi de $77,3 \%$ $(17 / 22)$, com resposta completa (RC) em cinco pacientes $(22,7 \%)$ e resposta parcial (RP) em 12 pacientes $(54,5 \%)$. O IO foi de 14/22 (63,6\%). Em 22 meses de seguimento, cinco pacientes faleceram, 1/17 do grupo que respondeu e 4/5 do grupo que não respondeu à quimioterapia. O endurado do TCHR foi maior em controles do que nas pacientes estudadas $(p<0,02)$, sendo também maior nas pacientes após a quimioterapia $(p<0,05)$. Ao BDI os niveis de depressão foram menores devido a diminuição da pontuação nos níveis somáticos e de desempenho $(\mathrm{p}<0,05)$. À ecografia, o volume do colo uterino após a quimioterapia foi menor nas responsivas do que nas não-responsivas $(p<0,001)$. A diminuição do tumor foi maior nas pacientes que responderam (74\% nas responsivas x $22,4 \%$ nas nãoresponsivas). A resposta à quimioterapia foi o principal fator prognóstico para as nossas pacientes.

Palavras-chave: Quimioterapia. Ecografia. Depressão. Colo do útero: câncer. 